\title{
Responsive environments: User experiences for ambient intelligence
}

\author{
Jorge Alves Lino*, Benjamin Salem and Matthias Rauterberg \\ Department of Industrial Design, Eindhoven University of Technology, P.O. Box 513, 5600 MB Eindhoven, \\ The Netherlands
}

\begin{abstract}
In this paper we review the emerging field of responsive environments as an ambient intelligence system with a focus on user experience. We see responsive environments as a combination between the scientific developments that resulted in Ambient Intelligence systems and the aesthetic motivation behind interactive art installations. This next development in Information and Communication Technologies transcends the computer screen and the localised interface towards ambient accessibility and experience. Inspired by different authors in the field of Ambient Intelligence, we redefine Responsive environments as physical spaces, such as city squares, public halls, etc, that are enhanced with the use of technology and media. The concept of responsive environments is defined in relation to ambient intelligence highlighting system-centred approach based on which it has been developed, and user-centred approach that we believe is the direction to follow. The infrastructure and technology required, notably the necessary sensors and actuators are reviewed in later sections. The user interaction is analysed with a series of examples. The different approaches to the interfaces are contributing to a better understanding of the challenges of selecting the right interaction principle. Furthermore, context awareness and user experience have an important contribution to the success of a responsive environment. An environment where the aesthetic of interaction, user engagement, access, embodiment and intimacy are also to be taken into account in the design and specifications phases.
\end{abstract}

Keywords: Ambient intelligence, responsive environment, user experience, ubiquitous computing, adaptive architecture

\section{Introduction}

We believe a next step in Information and Communication Technologies (ICT) is emerging, transcending the localised interfaces (such as speakers, displays, and other devices) towards ambient accessibility, with the aim of enriching the user interface and yielding a positive responsive experience. In this line of thoughts, Ubiquitous Computing (UbiComp) and Ambient Intelligence (AmI) have emerged as some of the next directions for ICT. While Ubiquitous Computing [61] is about providing universal and permanent access to information, AmI is about using this access to increase the quality of the experience that a service or content are providing. In general, an AmI system enhances the physical space through technology, media and services. According to Aarts [1], AmI is defined as a combination of context awareness, ubiquitous computing and natural interaction.
- Context awareness is the ability of a system to be aware of the users' context, their desires, whereabouts, activities, needs, emotions and situations [38]. Context, as defined by Meyer and Rakotonirainy [38], means the circumstances or situations in which a computing task takes place. The context awareness of AmI is achieved thanks to a network of sensors. The sensor data is combined to extract meaningful information on users and their environment (e.g. a context aware living room [28]);

- Ubiquitous computing provides access to content and services throughout the environment, while making this access invisible to the user [61]. In the context of AmI, UbiComp refers to the level of accessibility achieved by means of computing power that is always available everywhere. This means that a user can access a certain application, services or documents, etc,

\footnotetext{
${ }^{*}$ Corresponding author. E-mail: jorge@jorgelino.com.
} 
at any time and any moment (e.g. a wireless network provides ubiquitous access to information, via internet);

- Natural interaction relates to the user interface paradigm; it is based on natural modalities such as speech, gestures and tactile movements [60]. It features a specific spatial aesthetics (given that it exists in real space) about how to integrate ICT to the real world, creating experiences that involve people's perception of the physical space [e.g. interactive surfaces with which users take actions with their own movements [10]).

We believe AmI is also about adaptation to the user, in the sense of the environment being reactive, interactive, perceptive, receptive or proactive. AmI is also about the personalisation level reached by the system, which can be about user identification, preferences, profile or model, and which forms the basis for the selection of which content or service(s) to deliver. User(s) needs, requirements and desires have to be addressed as well [50].

Based on this understanding of AmI principles, the purpose of this review paper is to identify and understand what characterises current features of ambient intelligence systems, to discuss the concept of Responsive Environments as ambient intelligence installations that focus on user experience, and how could an ambient intelligence system focusing on the user experience be like, notably in terms of applications, interaction principles, and user satisfaction.

\section{Current ambient intelligence systems}

Early developments of AmI were marked by projects related to ambient access to information. An interesting example of ICT integration into an ambient installation is the Living Memory project, designed by Philips Design [35,56], aims to help people who share a locality (e.g. an urban neighbourhood) to interpret and preserve the richness and complexity of their local culture. It consists in the installation of touch screens in locations such as a bus stop or a cafe, where users can have access and information to issues, news, events or adverts. Using tokens that are scanned by the installation to identify the user, information can be swiped, bookmarked and stored, for later access any of the locations the installation is present. Furthermore, this information can be fully accessed, and if multiple users are present, it allows sharing annotation and retrieving by other users. This

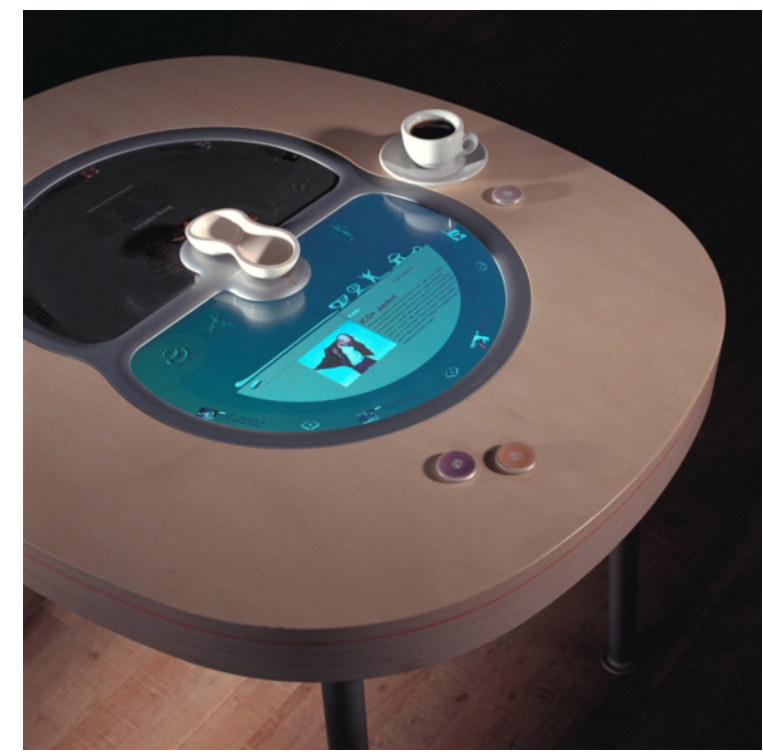

Fig. 1. Living memory, by Philips Design, Netherlands, 2004 [56].

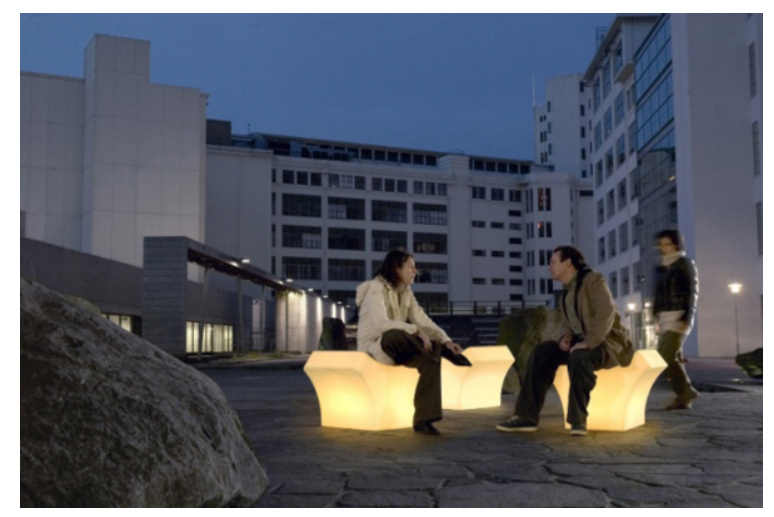

Fig. 2. Glowing places, by Philips Design, Netherlands, 2005 [24].

way, the information that is stored in different contexts (bus stop, cafe, etc.), that characterise part of the day, and living, of the user, can be shared and accessed by multiple users.

Another interesting example, also developed by Philips Design, is the project called Glowing Places [24].

Glowing Places is a concept from an investigation into innovative ways for people to interact with light in public spaces. The plastic seating, embedded with LED (light-emitting diode) strips and sensors, measure the presence of people over time. Both the number of people sitting and the length of time they stay create a 'social interactive pattern' that is translated 


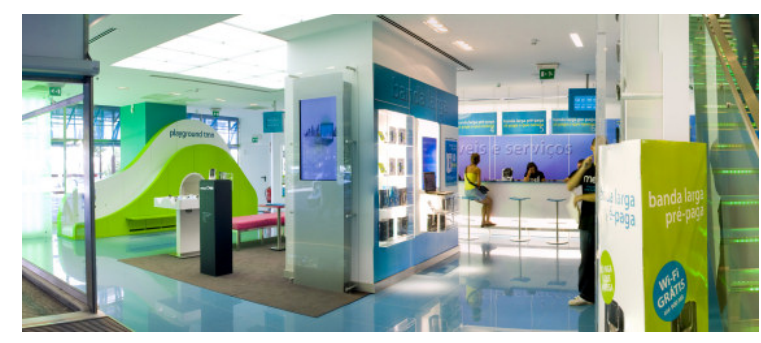

Fig. 3. TMN Bluestore, in Oporto, Portugal, 2008 [59].

into lighting effects in the furniture. Many people sitting for brief periods of time result in lighting activity expressing a busy period, whereas one or two people sitting for a longer period trigger mellow lighting. Glowing Places is built to respond to the behaviour and feelings of its users by visually expressing their activities. With this in mind, Glowing Places demonstrates the importance of lighting to signify the changing emotional states.

Early AmI projects have been developed based on a system approach that focuses on technology. This design approach considers that the system is deciding what is happening rather than the user [2]. In the context of shopping environments, public spaces that are massively visited every day, an example of such approach is the TMN Bluestore (see Fig. 3), in Oporto, Portugal, designed by Ydreams [59].

Visitors are received with a "mind-reading" video projection, where comic strip balloons pop sentences up over their heads and entice them to enter and explore the shop. Moreover, several services are provided via touch screens, where users can browse through digital catalogues. The space was enhanced with an area to play games and change the environment's lighting by sending a text message. Features are provided via natural interaction. Products are provided in a smooth way. The environment monitors the user and is adaptive. However, the experience is mostly entertaining, and does not really provide an added value to the experience of shopping. In this sense, systems designed under a system centred approach can be generally defined as enhancing physical spaces through technology and media, and providing ubiquitous access to services and content.

The Philips Shop Lab [19,46], a laboratory environment designed by Philips Research (see Fig. 4), and the Prada Soho Shop (see Fig. 5), in New York, designed by Rem Koolhaas together with OMA Architects and IDEO [41] are examples of AmI systems for the retail industry. The Philips Shop Lab is an AmI application that provides access to extra information about products in a shopping environment.

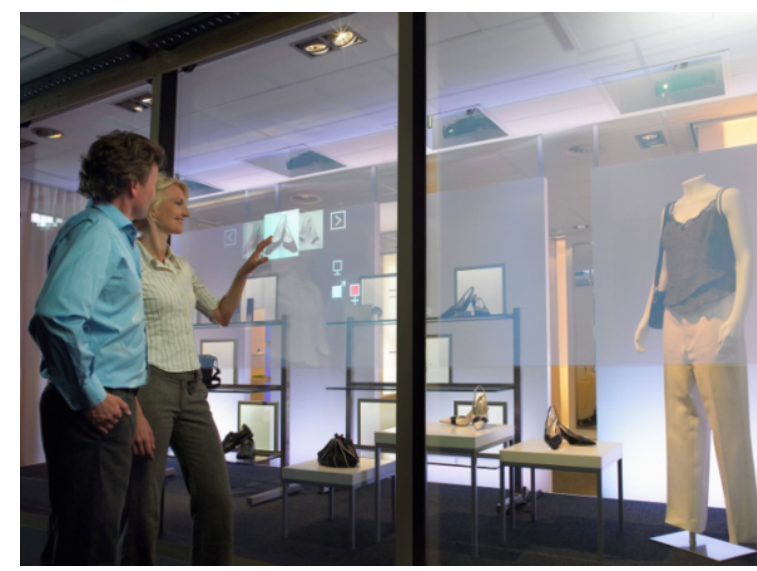

Fig. 4. Philips Shop Lab, in Eindhoven, the Netherlands, 2006 [46].

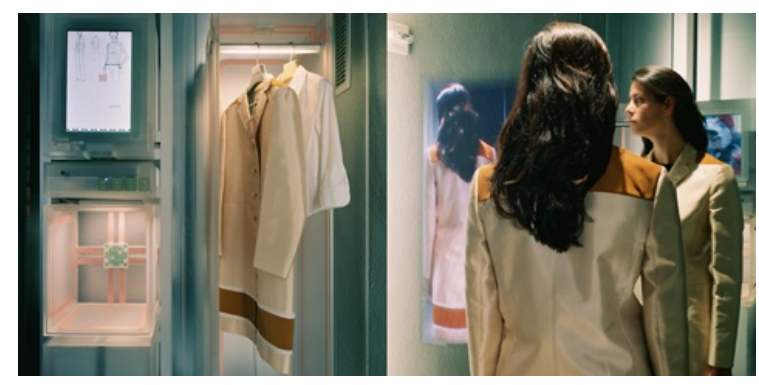

Fig. 5. Prada Soho Store, in New York, USA, 2001 [41].

The focus is given to the functionality, which in this case is to display and identify items that the user might be interested in buying, and provide extra information about them. In fact, we concluded that the user acts if it was a technology space while visiting the shop, instead of acting as (s)he would regularly in a shop.

The goal is to explore the different features and services provided, rather than getting to know the products that are being displayed. This is however expected, since this is a laboratory environment, where the concern is not directly connected to branding.

On the other hand, the Prada Soho store provides an example of a different kind of design strategy. The different environments that are being developed are centred on what could assist the user in the shopping experience, and the way the different services are there to be provided. The interactive dressing rooms improve the experience of trying on clothes for the customer and enhance the relationship between the sales assistant and the customer. There is a device that enables sales assistants to devote all their atten- 
Table 1

Characteristics of an AmI System

\begin{tabular}{|c|c|}
\hline Criteria & $\begin{array}{l}\text { System-Centred Approach } \\
\text { (focus on ICT integration) }\end{array}$ \\
\hline Infrastructure & $\begin{array}{l}\text { It is based on the delivery of universal } \\
\text { access and availability (e.g. Barclay's Inter- } \\
\text { active Walkway [4], Interactive Surfaces } \\
{[10] \text { ). }}\end{array}$ \\
\hline Interaction & $\begin{array}{l}\text { It takes place at the main focus of the user's } \\
\text { attention. The environment main purpose is } \\
\text { on delivering functionality rather than an } \\
\text { overall experience. Interaction is, in this } \\
\text { case, invasive, in the sense that it interrupts } \\
\text { the user, and it requires direct attention (e.g. } \\
\text { BPI Interactive Loan Store [8], Isola dei } \\
\text { Famosi stage [29]). }\end{array}$ \\
\hline $\begin{array}{l}\text { Context } \\
\text { awareness }\end{array}$ & $\begin{array}{l}\text { It happens, in this case, thanks to a descrip- } \\
\text { tive process by collecting, processing and } \\
\text { exchanging quantitative variables. Contexts } \\
\text { are described and classified using sensor } \\
\text { information and system instances, which } \\
\text { results, essentially, in a description (e.g. Car } \\
\text { wind shield in Wired [14], Vodafone Cube } \\
\text { [41]). }\end{array}$ \\
\hline Adaptation & $\begin{array}{l}\text { At this level, systems are receptive, since } \\
\text { adaptation is based on user explicit and } \\
\text { implicit inputs and the context where these } \\
\text { inputs are acquired (e.g. Smart Home [53], } \\
\text { Jayshree installation [12]). }\end{array}$ \\
\hline $\begin{array}{l}\text { User } \\
\text { Experience }\end{array}$ & $\begin{array}{l}\text { The system is designed mainly around the } \\
\text { available interaction processes. } \\
\text { The system is set with the aim of achieving } \\
\text { optimal balance between usability and } \\
\text { functionality (e.g. Interactive Ads [27], } \\
\text { Glowing Places [24]). }\end{array}$ \\
\hline
\end{tabular}

tion to customers and frees them from trips to the back room or to the computer. The device scans staff tags and customer cards, allows inventory checks, reserves dressing rooms, acts as a remote control to access information on the store's ubiquitous screens, and allows stock to be ordered and delivered. The design approach is not centred on the display of the technology, but in the experience that the users can achieve from the different spaces to be used. In this context, the enhancement of media and technology is there to assist the experience, and not as a technology experience per se.

Based on the AmI projects that we analysed, we can classify them according to criteria as listed in Table 1, which will be discussed on more detail in the following chapters.

We selected these criteria because they allow us to have a good overview of the various AmI systems and how they compare. One of the first outcomes of using these criteria is the clear absence of a system that fulfils them all in a balanced way. What also

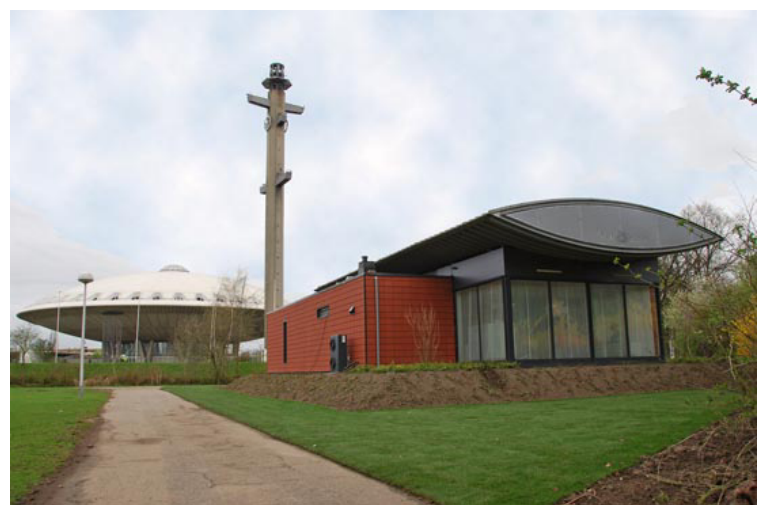

Fig. 6. Smart Home, Eindhoven, the Netherlands, 2008 [53].

seems to be the case is that systems are designed to address some criteria rather than the others.

\section{Infrastructure}

In this context, we refer to infrastructures as the physical structures and the building of the installations into the environments for which they are being designed. As an installation, an AmI system is a physical environment enhanced with technology. The enhancement implies the use of sub-systems that are embedded into physical objects, infrastructures and the different components of the environment surrounding the user. For example, if we consider an office environment, this refers to combining software that provides office tools that are somehow connected with the products that surround the user, e.g. lights, air conditioning, sound, etc. Obviously, this example can be expanded to other fields. One could be the home environment, e.g. living room that adapts to the different activities that can take place there; another interesting example is shopping environments, where enhanced shops assist users by providing information; public environments such as public squares, shopping environments, airports, etc, are also very interesting environments for further developments, especially if considering multiuser experiences.

On the other hand, home environments, such as living rooms with intelligent media centres, can involve more complex systems, given that they are more private and can acquire a higher level of personalisation, such as home utilities that provide users what they want and need considering the context, e.g. the way the levels of lighting adapt to the activities users are performing in the living room of the Smart Home [53], developed by the Smart Homes Founda- 
tion, in the Netherlands, and currently established in the city of Eindhoven.

\subsection{The role of sensors and actuators}

The enhancement of the environment, by means of sensors and actuators, provides the designed environment with the ability to, on the one hand, observe and recognise user's behaviour and context, and on the other hand, act upon or react to the user. It is about providing interactivity with users, and this reshapes the way we live and experience spaces [55]: the same way we use five senses to perceive and understand the contexts in which we live, spaces need to have the means to acquire information in order to locate users, understand what they are doing and provide a response. Metaphorically, sensors could be considered as the system's senses, whereas actuators are system's means of expression.

Acquiring information is achieved thanks to the integration of sensor technologies (e.g. motion recognition, expression recognition, speech and sound recognition, as in the Prada Soho store [41]) that allow the system to acquire data about the user (e.g. what is the user doing, where is the user, etc., as explored in the Ada Experience project [18]) and context (e.g. time of the day, weather conditions, etc., as used on the House of the Future project [28]). By having this information, the system can either be reactive to a certain event, stimulation of behaviour, or be proactive in the sense that the system takes the initiative of taking an action, that is adjusted to the user and context data acquired and therefore is adapted to the user's behaviour. In order to create an interaction that provides media and content (e.g. information) that are meaningful from the user point of view, these sensing technologies need to be reliable and robust, in the sense that the data collected and processed must be accurate in regard of the situation and context that is being analysed. The systems developed are robust if their performance is able to cope with variations (different user actions, for example) without loss or alteration of functionality. An example of loss or alteration of functionality would be a situation where several users are present at the same location, and the system misinterprets which one is actually using it, therefore reacting upon the wrong user action or behaviour. A system that reacts on a certain user movement takes in account that different users might have different sizes and ranges of the same movement (e.g. as it happens in the Glowing Places projects, previously mentioned). This usually requires complex

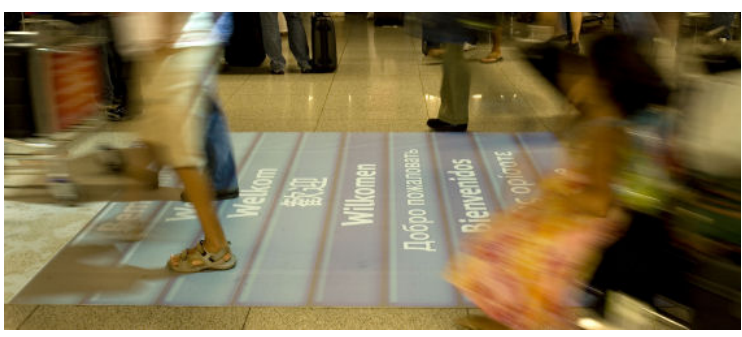

Fig. 7. Barclay's Interactive Walkway, in Lisbon's International Airport, Portugal, 2008 [4].

technologies, such as movement and sound recognition, providing ubiquitous access to the services and content. Providing ubiquitous access can be a speech recognition system that translates instructions to a telephone, within a car environment - such systems can be found in, for example, some editions of Peugeot 307 and Fiat Bravo. In this context, by providing ubiquitous access to services we mean, for example, placing a phone call or accessing the inbox via bluetooth hands free set connected to one of such cars. Within the same context, by providing ubiquitous access to content we mean, for example, giving access to the user's phone directory or inbox content accessible in one of these car's memory.

Among the different families of sensors that can be applied, the most common used input methods are pressure sensors (e.g. Glowing Places), touch screens (e.g. Living Memory), RFID tags (e.g. Prada Shop), motion recognition (e.g. TMN Bluestore) or microphones (e.g. phone control in cars).

An interesting example is the Barclay's Interactive Walkway [4] at Lisbon's International Airport, designed by Ydreams for JCDecaux Airports (see Fig. 7). Users easily find their way out of the baggage claim area of the airport, by following the walkway that welcomes travellers in different languages. By means of motion recognition, the walkway is triggered by motion detection and proximity of the walkway, enlighting the way through which users should circulate

In this sense, the richness (diversity) and uniqueness (particularity) of the experience are related with the fact that the original experience in a certain space is being enhanced, and results into a new individual experience, that is no longer the same as before. This depends on the satisfaction (where result corresponds to expectation), the fulfilment (achievement), and enjoyment (pleasure) reached.

The enhancement of physical spaces with AmI systems defines new trends in architecture that merge 


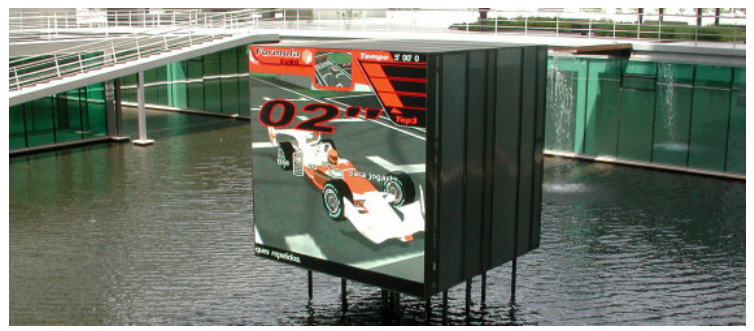

Fig. 8. Vodafone Cube, in Lisbon, Portugal, 2002 [41].

digital content and real spaces. A good example is the urban installation Cube (see Fig. 8) at Vodafone headquarters in Lisbon [41].

Users (both Vodafone employees and visitors) passed by the installation and called a number displayed on the screen. Once connected, users would then join a live game, with up to six other real-time players, exchanging SMS with the between their own phones and the number displayed in the installation. As Vodafone staff has reported it, entering and leaving the headquarters became a fun experience. The installation displayed how users should operate their mobile phone. On the other hand, it was not clear if and how the systems displayed which onscreen character belonged to a specific phone and neither if users could choose which game to play.

As for the role that infrastructure plays in the context of installations, it is worth mentioning that this is a feature that doesn't live on its own, but depends on others to, together, constitute the kind of installations we are aiming at. As we have seen in the previous examples, the different kinds of technologies or infrastructures that are explored are pretty much depend on the decisions made in regard of the interaction models that are explored in each case. In the following section, we will review examples of interaction models that can be explored in this context.

\section{User interaction}

In general, the history of interface and interaction design tends to be one of simplifications of the complexity of interfaces [60]. Such process expanded to AmI interfaces deeply influences current design practices, because one of the challenges that interaction designers face is to help users to manage the complexity of such systems and their interfaces. The current trend is to use embedded technology, invisible to the user, which supports the interaction within environments.
As an example, recognition technologies (e.g. motion recognition, speech recognition, etc.) are integrated into the system to allow people to interact with computer-based systems the way they would with other people, acquiring multimodal forms between application and user, such as gesture, voice movement and context recognition [9]. Such kind of interaction is spontaneous and straightforward, from the user point of view, and is known as natural interaction.

\subsection{Natural interaction}

Natural interaction is defined in terms of experience: people naturally communicate through gestures, expressions, movements, and discover the world by looking around and manipulating physical things, providing users the perception that what they are interacting with is real and usual $[38,60]$.

An AmI environment provides interactive and communication application through natural inputs, such as gestures, sounds, body motion, etc. Other promising directions are facial expressions [43], footsteps inputs [44], and hyper-reality interface [7]. This expands the general concept of multimodal interfaces, where the interaction is based on different modalities such as vision and hearing. The interaction is not anymore dependent on a specific, unique user interface, but on the recognition of the user's actions and behaviour. This kind of interaction, known as natural interaction, is defined in terms of experience: people naturally communicate through gestures, expressions, movements, and discover the world by looking around and manipulating physical things [60].

AmI systems acquire data about the user and context, and present digital content as it was part of the physical environment, assuming the interaction design is intuitive and needs no explanations. The environment itself can be embodied with interactive properties [47], complemented often with active forms [21], objects that interact by changing their shape and adapting it to the context.

An interesting example is the way large displays become interactive surfaces (see Fig. 9), by means of movements and proximity between the user and the display surfaces [10]. The images projected represent water, for example, and the effect that the user interaction triggers gives the user the impression of really moving their hand inside water.

Natural interaction on physical spaces defines new trends that merge digital content and real spaces. This allows the user to manipulate and interact with an application having the feeling of manipulating reality 


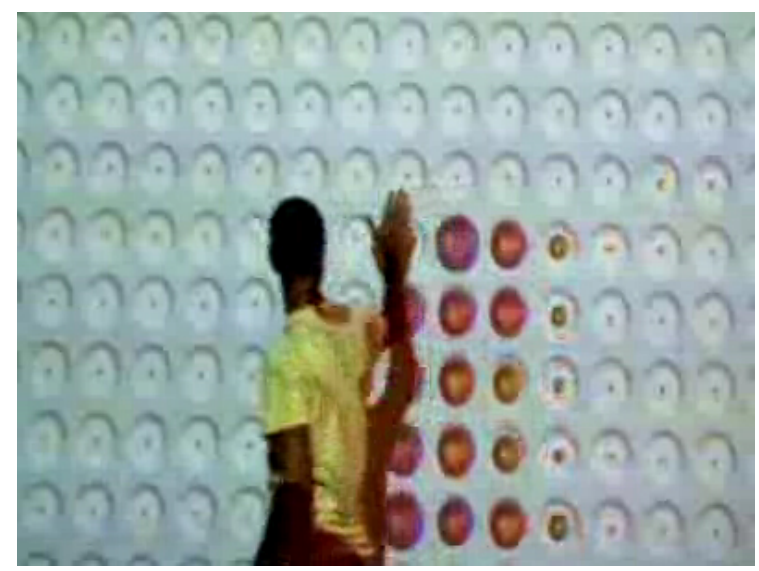

Fig. 9. Interactive surfaces designed by iO Agency [10].

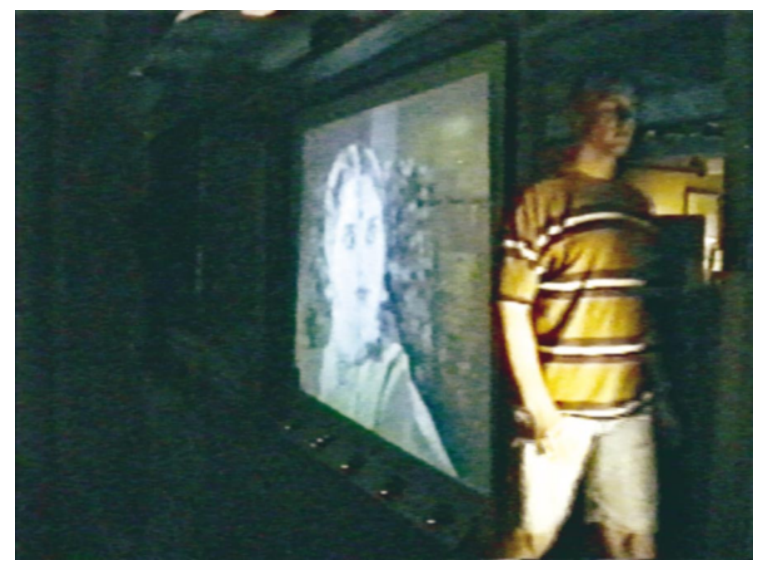

Fig. 10. The dancer staring at the user that abandons the installation before ritual is finished [12].

itself [55]. According to Valli [60], if users in public spaces may spontaneously interact with the designed artefacts, there is no feeling of being the user of a computer application, but manipulating a reality itself.

Within the scope of AmI systems, and given the tendency for technology to be embedded within the infrastructure, this interaction model is directly related with the concept of natural interaction systems [1]. An interesting example of an application that naturally induced the feeling of dealing with reality is the experiment developed within the MIT Media Lab with Jayshree, an Indian temple dancer [12].

In the installation, the image of the dancer Jayshree was displayed, looking back and forth scanning for an audience. As soon as a passer-by entered the space, Jayshree prepares herself and performs her dance of welcome. If the visitor leaves before the dance is complete, the display changes to a close-up

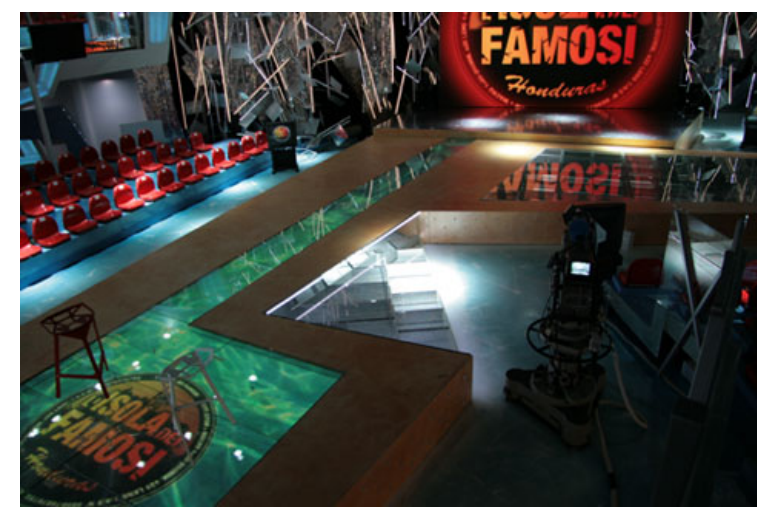

Fig. 11. Isola dei Famosi stage, Italy, 2007 [29].

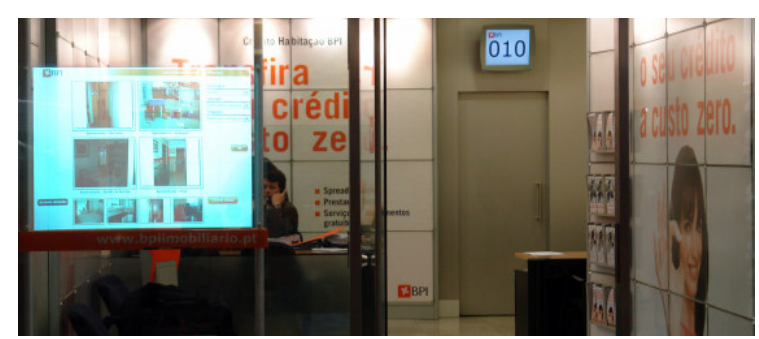

Fig. 12. BPI Interactive Loan Store, in Lisbon, Portugal, 2006 [8].

of her staring at the departing audience (see Fig. 10). This piece engaged passers-by and, according to audience reports, made those who left the installation feel a little guilty. This feeling is triggered as if the visitor was interacting with the dancer herself, and not just an application.

In order to provide this experience to the user, natural interaction uses embedded technology into the environment, making it invisible to the user. An example of this invisibility is the interactive furniture and displays designed for the stage of the Italian TV show Isola dei Famosi [29], where such interactive surfaces are applied to the creation of a TV stage (see Fig. 11).

By integrating the technology into the environment, it becomes completely invisible to the user, where interacting is not intrusive for the user and becomes a natural way of acting. In this case, the enhancement is fully integrated into the environment, and improves the dynamics and experience of the set, not being an isolated experience on its own.

An example designed by Ydreams [8] for the BPI bank uses the context of a bank (see Fig. 12). Public displays are used for advertisement presenting digital brochures, in which users navigate through different parts of the brochure being shown with an arm 


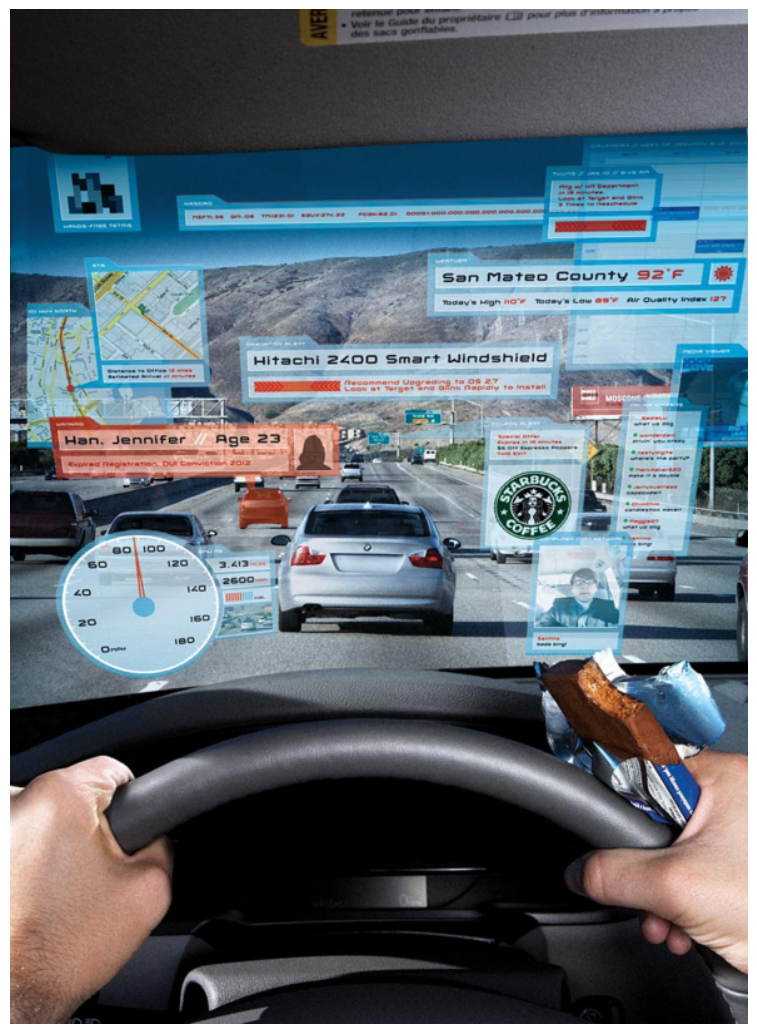

Fig. 13. Car windshield interface showed in wired magazine [14].

movement that represents the movement of turning the pages, as if real pages were being turned. This installation had the goal to create a dynamic and immersive environment where access to information is transparent and effortless to the user. All integrated applications involve the customer in intuitive, handson experiences. That includes an interactive window built into the storefront that detects passers-by and invites them to explore BPI related services, and a floor projection, which reacts to movement. There is also an intelligent ticket system that lets customers enter their mobile phone number in order to receive a text alert when their turn is up.

It is however important to manage information and to avoid overloading the user. An extreme example of information explosion is presented in the wired magazine website [14], a car windscreen would be enhanced with all the extra functions and information that could be support to the activity of driving (see Fig. 13).

Even though these functions and content could provide extra information or assistance in driving, their presence and availability on the main focus of attention of the user would actually interfere in the

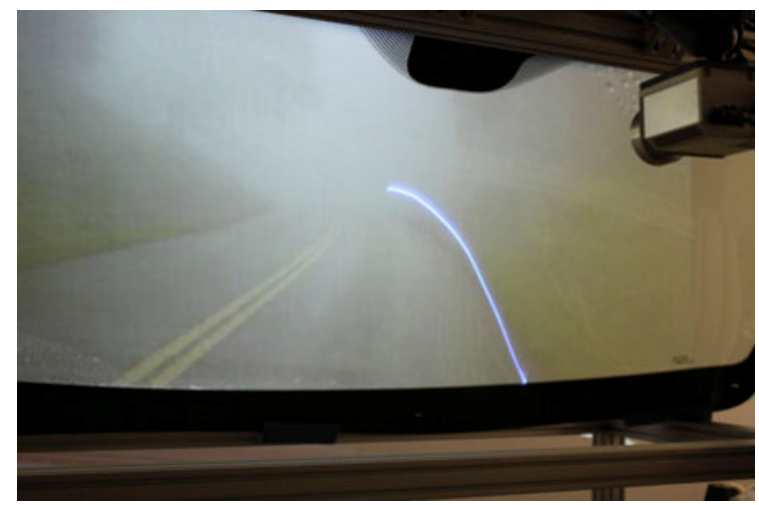

Fig. 14. Car windshield interface designed by General Motors [23].

safety of driving. While the system makes available a considerable amount of extra information and functions, it contributes negatively to the experience of driving by impeding the road visibility.

In the next example, developed by General Motors [23], the windscreen combines laser, a camera and infrared sensors to enhance the visibility of objects on the road (see Fig. 14). The windscreen display focuses on selected objects on the road in front of the driver; this is to avoid unnecessary information for the user. For instance, the infrared sensors would detect and highlight a user pushing a baby stroller in front of you. And on a foggy night, the lasers would outline the edge of a road. This case exemplifies how can ambient information support the action of driving, but being ambient, the main attention of the user is still dedicated to the driving itself, and the enhancement via this ambient information provides a higher awareness of the road conditions, therefore providing a higher level of safety.

The different interaction models that are explored are so, as we have seen, depending on the context of use. In the next section, we will define context, the importance of context awareness in the design of environments and installations, and examples of use to illustrate some of the followed directions.

\section{Context awareness}

Context, as defined by Dey et al. [15], consists of information that can be used to define the situation of entities (e.g. a person, place or object) that are considered relevant to the interaction between a user and an application. The process of context awareness consists of describing and classifying the contexts 


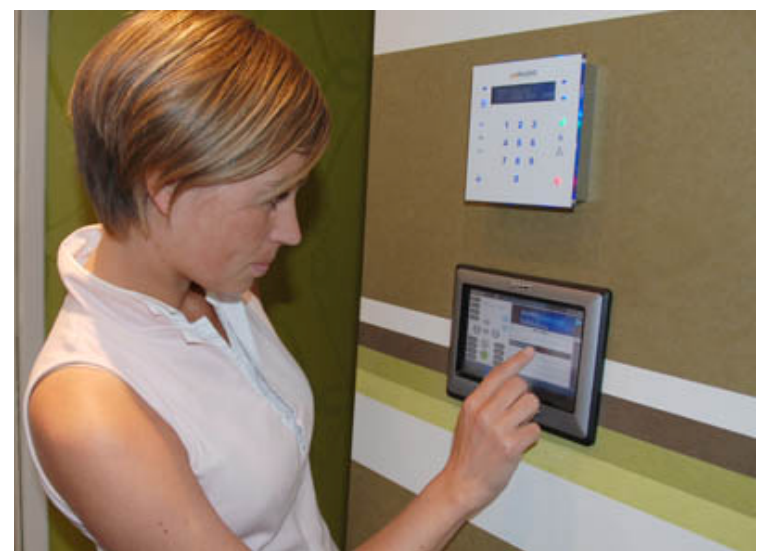

Fig. 15. Air-conditioning and light control panel in the Smart Home [53].

within a certain environment, using sensor information and system instance description (e.g. user location and activity).

This can be achieved by means of collecting, processing and exchanging quantitative variables, such as user gestures and positions, temperature, level of lighting, etc. This information is processed by the system to ensure a correct classification of the context and a corresponding adaptation of the environment. Within the field of adaptive home, a simple example is an automatic air-conditioning and light setter, based on the temperature and light conditions of outside, as we can see when visiting the Smart House (see Fig. 15).

Dourish proposes an approach to contextawareness [16], in which the context where actions take place is considered the key factor that makes an experience meaningful for users. Contexts play a critical role in defining actions and in providing users with the means to interpret and understand action. This is because users have previous experiences that contribute for the way they perceive new ones. These previous experiences were made in particular contexts. Therefore, if contexts where new experiences are designed are somehow related with previous ones, then it becomes easier for users to find a meaning in the new experience.

Within a context, AmI systems should be flexible enough to understand the variations of actions or behaviours that different users can perform. Such adaptability requires combination of different contextual information, combining environment information with user information. Having access to contextual information, the system is able to trigger affect on the users, based on the present environment conditions,

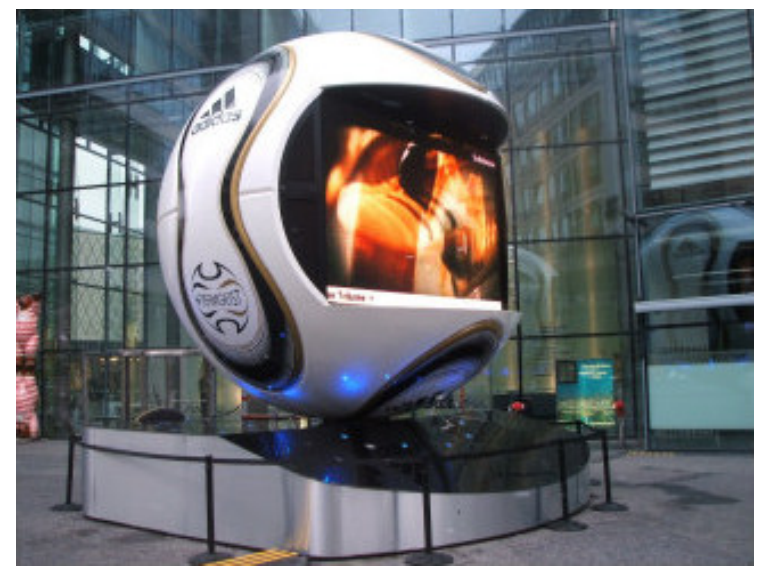

Fig. 16. World Cup Adidas Eye Ball, in Barcelona, Berlin, Cologne, London, Manchester and Paris, 2006 [63].

but considering the user's particulars as well [51]. Coming back to the Smart Home example, if a user turns the lights on, the system will provide a different level of lighting depending on what the user is doing (e.g. if watching TV, the light will be dimmed).

Since AmI systems are designed in order to provide an experience that is meaningful, temporal context is also involved, as actions and changes gain their meaning and intelligibility from the way in which they figure as part of a larger pattern of activities (e.g. the activity pattern of a house family) [28]. In this case, context awareness is based on interpretation of the different variables that constitute the experience, understanding, for example, that family patterns are ultimately constituted by individual patterns from each of the family's members, and therefore, the contextual information within the same space is not exactly the same for each member. An example is the situation where one family member is reading and another family member is watching TV. Which one to prioritize when defining the living room light conditions? The system should be constructed to enable a reasoning and understanding of current contexts and current experience the user is having, because, as seen on this clear example, one way to make the system adapted to this reality would be to reflect the rules or patterns that already exist in the household (e.g. a parent would have priority of choice over a child). An example of a context-aware system implemented within several simultaneous users is the urban installation World Cup Adidas Eye Ball (see Fig. 16), installed in Barcelona, Berlin, Cologne, London, Manchester and Paris, in 2006 [63].

Within this installation, users are detected by the system in the surrounding area of the installation. The 
installation provides users with football news, weather information and Adidas related topics. Furthermore users can connect with their mobile phones and interact with the system through games and competitions. The installation has two functions: spreading information and engaging users in interaction. The installation is linked to a current major event sponsored by the client, and users become aware of this. Moreover, the installation travels around the world, connecting to more and more users.

However, the negative side is that the interaction requires a mobile phone, and as far as the user experience is concerned, there's not really a personalised interaction between the users and the system, as the system is designed to deal with a mass audience, which, at the end, provides pleasure in using an urban installation, but it does not provide a really meaningful experience.

As we have seen, context awareness refers, essentially, to a system's ability to acquire information. In the next section, we will explore how context awareness influences the adaptation level of a designed system, taking in account that if, in one hand, context awareness is acquiring relevant information about the surrounding entities, adaptation refers to, on the other hand, to the changes and output provides by the environment based on the previously acquired information.

\section{Adaptation}

The adaptation to the users can have many levels, from using a simple presence sensor, in order to identify a user is present, e.g. Barclays' interactive walkway, to expression recognition in order to determine the user's mood and have an emotional adaptation (e.g. Ada Experience). In the case of the Barclays' interactive walkway, the system is somehow adaptive, in the sense that it identifies whether travellers are arriving or not. However, the system is not personalised, given that the messages are given in different languages. Adaptivity, in this sense, is merely related with the positioning of the travellers, and not really to their identity.

In most cases the adaptation is related to the features and context of the environment and can also be about the services (that can be adaptive in regard of the specific features of the user) delivered within the environment.

We have set up a scale that defines five levels of adaptation [49]:
1. At the simplest level, adaptation can be just a reaction to user inputs (e.g. keyboard). Reactive systems are impersonal and require an input from the user for any change.

2. In this case, adaptation can also be interactive. In which case there is a dialogue between the user and the environment and, in some cases, the identity of the user is relied upon as part of the inputs, bringing personalisation to this level of adaptation (e.g. computers).

3. More adaptive systems are perceptive. They also rely on user implicit input (e.g. user activities or actions), rather than just explicit input (e.g. operating a control panel, Smart Home). Perceptive systems try to address user preferences and deliver services accordingly.

4. Adaptation can go further and the system can become receptive, taking into account the context of use. The adaptation relies on user profiles (e.g. Amazon.com) to deliver tailored services and content.

5. Finally, we believe the ultimate adaptation level is when the system turns proactive and is able to predict user needs and actions according to a model.

All the features that are part of the design process of an AmI installation mutually influence each other. Infrastructure is built upon the technological and physical needs that the designed environment is aiming at; interaction models are selected and designed towards a positive usability quality, that takes in account user needs, wishes and contexts of use; surrounding contexts, and the ability to acquire date about these, allow the system to act or react by adapting to the different condition that the system is facing. But ultimately, the whole interest of taking these features in a combined consideration is to achieve and provide user experiences that are more than just a reflection of positive usability. In the next section we will be analysing the concept of user experience, in what level can these features be combined to achieve positive experiences, and to which extend can user experience be a definitive motivation and goal along the whole design process of AmI installations.

\section{User experience}

The term user experience has been explored since the middle 1990's, but, so far, there is little agreement on a unified notion or view on what exactly defines user experience [34]. While early perspectives saw 
user experience mainly as a result of user interface design, many researchers believe that positive user experience comes from the value and meaning of the product concept itself [48]. User experience focuses on "non-utilitarian aspects of human-technology interactions, shifting the focus to user affect and sensation" [34]. This is one of the reasons why, being a subjective and holistic concept, it is not easy to create criteria based on which it could be evaluated.

In the context of interactive systems, Forlizzi and Battarbee have explored three types of experience, from the meaning point of view [22]:

1. Experience, referring to the constant stream of "self-talk" that happens while we are conscious, and that is based on the holistic knowledge one has acquired during the course of his/her life. E.g. while walking in the park or performing light housekeeping.

2. An experience, referred to as something more unified, that could be articulated or named, having a beginning and an end, and could eventually constitute a learning point from the holistic point of view. E.g. a particular event or a particular product that one interacted with at a certain moment.

3. Co-experience, which involves creating meaning and emotion together, or shared with others. Shared experiences allow a range of interpretation by others involved, and therefore personal experience is mutually influenced by sharing and expressing meaning through social interaction. E.g. interacting with others during a particular event.

In the context of AmI, according to Aarts and de Ruyter [2], AmI systems' first priority should be to contribute to the development of products and services that are easy to use and simple to experience, and not the mere increase of functionality, because otherwise these are developed without proper consideration for the effects it will have on the user [2]. In the context of AmI, the user experience is the experience one has while interacting, using and manipulating a product, a process, a service, an event, or his/her environment, it is a combination of interaction and perception. The interaction relates to the relation between the user and the environment as an ICT system and a physical space. The perception is the combination of visual and audio as well as other media and modalities changes produced by the environment.

Hassenzahl and Tractinsky [26] defined user experience as the consequence of:
- The user's internal state (e.g. pre-dispositions, expectations, needs, functionality, mood, etc.),

- The characteristics of the designed system (e.g. complexity, purpose, usability, functionality, etc.) and

- The context within which the interaction occurs (e.g. social setting, meaningfulness of the activity, voluntariness of use, etc.).

Such a definition focuses on how to create quality experiences rather than merely preventing usability problems and supporting functionality.

As previously mentioned, there is still no widely approved definition for user experience [48]. However, after analysing some of the different perspectives so far $[2,3,13,20,22,26,34,45,48]$, we believe that user experience design is about designing for subjective aspects: pleasure and value, in contrast to eliminating usability problems. It is a subjective and holistic concept that is hard to measure and evaluate, since the same design can have a different effect over different users in different times, affected by the user's internal state, context of use, and the system used [48].

Designing a user experience is about addressing the relationship between an application running on an ICT system that can be represented as a series of computations and experiences that are essentially internal mental events [13]. In this perspective one has to understand that the experience cannot be the media, the services or the environment, it can only be part of the interaction, as a process linking the user internal state with the various states of the ICT system. The challenge is then about the design, selection, rendering and manipulation of the environment and the services offered so as to trigger a desired user experience.

The user experience delivered out of an AmI environment is therefore about affect and motivation. Affect to have certain emotions and, motivation to perform a certain action or adopt certain behaviour. Within an AmI environment the user experience combines interaction and perception experiences. The interaction experience relates to the relation between the user and the environment as an ICT system and a physical space. The perception experience is the combination of visual, audio and sensory changes produced by the environment. In a static environment, the physical experience of building materials and their sensory properties, as well as the spatial geometry of an environment, define the user perception. In a dynamic and changing environment, the user perception is further influenced by the relation between the 
dynamic aspects of the environment and her/his behaviours and actions. It is about generating the perception of an environment yielding a changing and responding space.

User experience design optimises the use and application ICT infrastructure within a physical space, the selection of services available and the design of the physical space. It is also about reduction of redundant or unnecessary features and the management of the relationship between users and their surroundings. An aesthetic perception of the experience is the outcome of combining this relationship with previous experiences the user had. This relationship triggers new ways of seeing and perceiving the experience the user is being subject to. This perception depends on the individual's interpretation, which may arise from emotional responses and/or comparison with previous experiences [20]. Technology plays an important role as it enhances an existing environment, to deliver positive experiences. The purpose and functions of the environment are embedded into a context, in which they are integrated and used [45].

As defended by Aarts [3], there is a paradox in the way AmI has been developed so far, in terms of accessibility and experience. The required technologies are embedded in the background providing functions for the user, but how are these functions related to the experience and meaningfulness on the perspective of the user? A system that is developed based on a usercentred approach, such as the Prada Soho Store or the Vodafone Cube [41], implies that, in its design process, technology and experience are matched in order to achieve results that effectively improve the user experience.

\subsection{User engagement}

Engagement, in the scope of AmI, is the level of involvement that an environment triggers in the user. An environment with displays will have users observing what is being projected. The information is provided via the displays, which could metaphorically be seen as a monologue. An example of such monologue is cinema, in the context of narratives, or screen billboards, in the context of advertisement, given that these are media that are looked or watched at, by viewers that end up having a passive role to what they are being presented. Traditional communication media, such as television, radio or print, assume a different role. New technologies and interactive experiences open the doors to new genres of experiences in the perspective of AmI, such as interactive

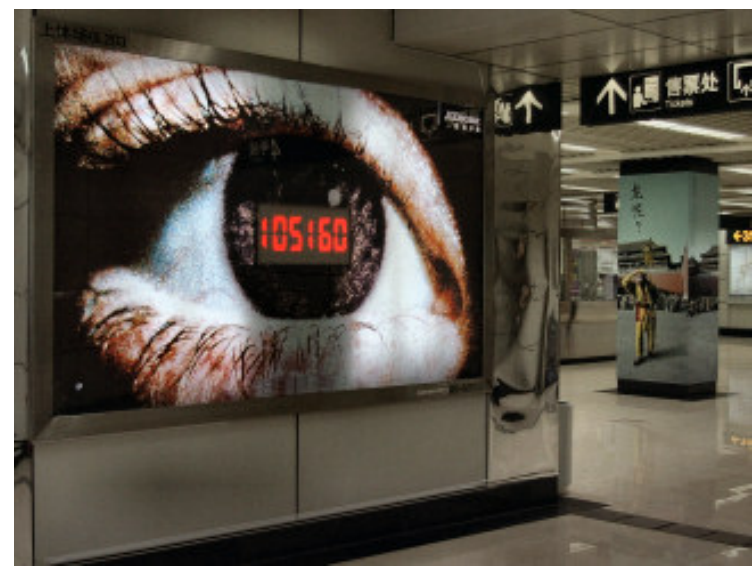

Fig. 17. Interactive Ads for Shanghai Stadium Subway Station, in Shanghai, China 2007 [27].

television, alternate reality gaming or interactive installations. An interesting example is the interactive multichannel game Black-beard Connection, which conquered huge audience in the Netherlands, making use of mixed media such as mobile communication, Internet, printed matter and television [5]. Information, entertainment and other contents are provided to the audience in the form of dynamic and interactive physical space applications, instead of the conventional static form, e.g. passive contemplation activities such as watching television, cinema or advertisement, as mentioned above. Users not only have direct contact with the information, but also gain an experience thanks to their engagement while interacting with the environment.

As we observed in the case of the Interactive Ads (see Fig. 17) for Shanghai Stadium Subway Station, in China [27], the interactivity offered to the user is quite interesting because it integrates the user in the advertisement that is being projected. The level of detail of the product advertised increases as the proximity of the user to the billboard increases. It allows the user to experience branding and product advertisement in an engaging way because the quantity of information provided is adapted to the amount of time the user is willing to spend looking at it.

However, it is questionable if the context in which the system was installed (a metro station) is the best context of application, given that this is a location where users are, generally, on the run, and will not likely stop to actually experience the installation. If the context of use of such installation was one where users do have to spend time waiting (e.g. airport lounges), such environment would actually take in 


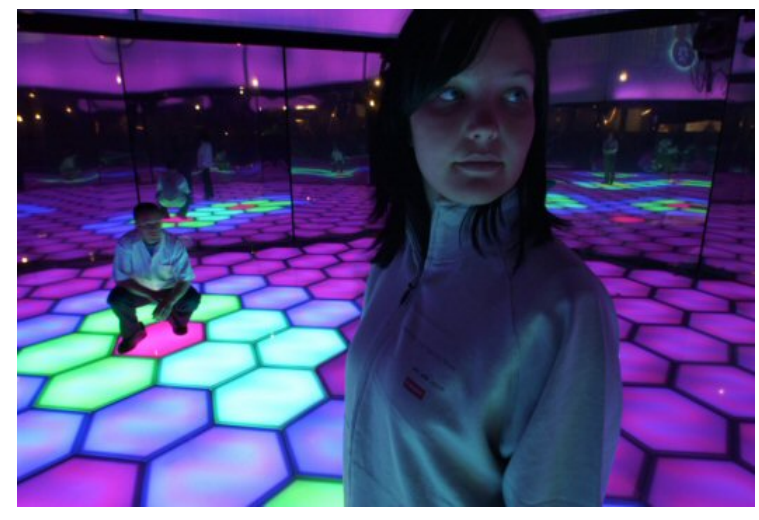

Fig. 18. Ada Experience, in Neuchâtel, Switzerland 2002 [18].

consideration the time that users have to wait by exposing them to such an environment and experience. To deliver engagement, the environment design should go beyond form shape, appearance, media and services, towards taking in consideration the emotional impact that such environment would have over the user.

On the other hand, the Ada Experience is an interesting example, it is an interactive space developed for the Swiss Expo in 2002 [18]. The Ada installation triggers the user's attention more efficiently and gives the user the feeling of being acknowledged, it engages the user into a dialogue with the system. Conceptually, this interactive space can be seen as an living entity with visual, audio and tactile input, and non-contact light and sound effectors. Visitors to Ada are immersed in an environment where their only sensory stimulation comes from Ada herself (and other visitors). Like an organism, Ada's output is designed to have a certain level of coherence. It can communicate with them collectively by using global lighting and background music to express overall internal states, or on an individual basis through the use of local light and sound effects.

The experience comes from the more encompassing combination of the aesthetics of the environment, the media, the atmosphere rendered and the user actions. These could be used as positive motivators for the user [36], encouraging users to experience the environment they are in, and feel positive towards it.

\subsection{Embodiment and intimacy}

By embodied technology, we mean technology that is invisible for the user and allow him to rely on the supporting technology infrastructure for the fulfil- ment of his/her tasks [58]. Within this context, we call intimacy to the proximity between the different environment elements that are embedded in the environment, and the users.

The integrated technology should as simple as possible while delivering the required functions [9]. This means that the technology is chosen for a particular application not because it is innovative and groundbreaking, but because it serves its requirements, no matter how simple they may be.

Within a AmI installation, the interactive features such as motion or speech recognition, can be present on the environment itself (via sensors and actuators), or can be embodied in physical objects. Embodiment is to attribute physical objects with characteristics that allow them to interact with a physical environment meaningfully (e.g. a living room can have a temperature sensor that sets the air-conditioning system, as opposed to having a controller, that embodies the control of the environment). The level of embodiment of technology onto an environment has implications on the relationship that users build with the environment. The intimacy of these systems provides different levels of effect and engagement, depending on how an object is embodied into the user (the object is felt like an extension of the user) or the user is embodied into the object (the user submits to the interactions of the object). According to Fels [21], and as explored by Blaine and Fels [6] and Costello et al. [11] there are four types of relationships that can be categorised according to the depth of embodiment:

- The user dialogues with the object, in which case the experience is put on cause and effect of this communication (e.g. a GPS navigator);

- The user embodies the object, in which case it is the control of the object as an extension that provides experience (e.g. playing drums);

- The object communicates with the user, in which case the experience comes about as reflection or contemplation of the signals coming from the object, as there is no interaction (e.g. thermometer);

- The object embodies the user, where the object must be able to control the user and the user must be in a state to allow the control (e.g. a massage bed). In this case, experience is drawn through relinquishing control of the users themselves so that the object can conduct them. The emotional response arrives through submission and belonging. 
The matter of embodiment and intimacy is of relevance for the design of AmI. By using interaction models such as natural interaction, embedding technology into the environment, systems are invisible to the user's attention. If a system is designed considering with a higher level of intimacy with the users, these will be able to communicate ideas and emotions effectively through the system, as if it was an extension of themselves [37]. If users in public spaces can spontaneously interact with the surrounding environment, with different levels of intimacy, there is no sensation of being using a system or application, but manipulating reality itself, which constitutes, on its own, a very promising perspective.

\subsection{User access}

Accessibility, in general, can be universal, areawide, local, or single point, depending on the goal that a system is aiming to achieve. In the case of AmI accessibility, in the context of the system (e.g. a building, a city...), is to be universal $[1,2,17]$. According to Emiliani and Stephandis [17], universal access implies the accessibility and usability of information technologies by anyone at any time or any place. Designing such access into a system requires methodologies and technologies that allow systematic and cost effective approaches to accommodate all users, taking in account that different users have different requirement and therefore the interaction should be flexible enough to provide different users a positive experience [57]. E.g., in the case of the Interactive Walkway [4], users are considered to approach it by walking, by default. But the installation should also work with wheelchair users, and in the case of blind users, users should be given sound feedback as a replacement of the visual messages being displayed.

However, as argued by Coen [9], universal access is not always the most appropriate accessibility level to AmI. Designing an intelligent and interactive environment may require highly embedded ICT structures. However, this does not imply either that the technology or application must be accessible everywhere in the environment, nor that users must directly interact with any kind of computational device [9]. By using an approach where minimal hardware modifications and "decorations" (e.g. cameras and microphones) are advocated in ordinary spaces this should enable only interactions that contribute to the designed and expected experience (in case of the Barclay's Interactive Walkway [4] the application is very specific about what information is being provided to the user). Depending on the nature and objective of a given system design, providing permanent universal access in a context where interaction with the user is taking place in a particular time and place is, on one hand, technology overkill, and on the other hand it is not clear whether the universal access is contributing for a user experience that makes sense.

\section{Defining responsive environments}

The way AmI systems have been developed during the first decade of the $21^{\text {st }}$ century had a background theory that pointed out the matter of experience. From a design point of view, some of the experiences resulted in interesting explorations of technology.

Back in 1977, Myron Krueger had explored the building and rebuilding spaces accordingly to experiences, taking in account that the technology developments were at that moment very limited, when compared with the current ones. Krueger created the concept of responsive environments as physical spaces that "perceive human behaviour and respond with intelligent auditory and visual feedback". This concept was introduced as the basis for a new aesthetic medium based on real-time interaction between users and systems that focuses on human experiences [32], based on the fact that this was an exploration that was mostly perceived as art. Responsive environments allow users to manipulate digital media via the surrounding environment thanks to verbal and non-verbal actions. Users become immersed in an environment whose content and appearance react to them [33].

In this perspective, and as an evolution to the concept of AmI that has been developed on scientific contexts, and the way Krueger explored the theme in an artistic perspective, we have approached and redefined responsive environments as physical spaces that are enhanced with ambient intelligence, e.g. media and technology to provide a user experience that is interactive, rich, unique and changing. Users of the environment experience a more engaging and interesting space when compared with the original space before the enhancement. A clear example is a shop with interactive features, such as the Prada Shop or the TMN Bluestore, which allows a different level of experience from a regular shop that just exhibits the selling products. The goal of the enhancement is to place the technology that the system uses in the backstage, being "hidden" or "invisible" for the user that interacts within this space. In the case of the TMN Bluestore, a light system that highlights the items to which the user is looking at allows the user to experi- 
ence the highlight, but not the complexity of the process that makes the system aware of where the user is looking at.

A responsive environment combines several adaptive components, such as light, temperature or sound components. As such, the environment can transform in many ways to adapt to its users. The transformations can happen in two ways: at one level, a structural transformation, in the form of the physical structure of the space itself by using, for example, movable panels and partition walls. On a second level, a content transformation, where the changes can relate to the content presented in the space. This content may include the media, the information and the interactivity available, e.g. wall-integrated displays or projections, Bluetooth messages sent by the system to your mobile phone, etc.

Within responsive environments, the user experience is a combination of interaction, perception and aesthetic experience. The interaction experience relates to the relation between the user and the environment as an ICT system. The perception experience is the combination of visual, audio and other media changes produced by a given installation. The aesthetic experience relates to the emotional feedback that the system unchains on the user. This means that the user experience is influenced by:

- On a first level, how the user interacts with the system;

- On a second level, what comprehension and understanding the user has over the experience that he's being the subject of; and

- On a third level, which emotional state the environment triggers on the user.

As responsive environments acquire data about the user and context, they can provide an action that is adapted to the user's behaviour and situation. This results in a personalisation of the environment to the user, as it gives him/her an experience of the environment where there are details and characteristics that are addressed by the environment and that are not necessary relevant to the service provided, but to his/her experience.

A responsive environment delivers a desired (expected) and designed (defined) user experience, via interaction between the user and the physical space. It is also via using space as a platform for a certain affect (the experience of a feeling of an emotion) and behaviour (the actions and reactions of the in relation with the environment). It is a space that invites to certain emotions, actions and state of mind, by de-
Table 2

Characteristics of a Responsive Environment System

\begin{tabular}{ll}
\hline Criteria & User-Centred Approach \\
& (focus on user experience) \\
\hline Infrastructure & The building of the infrastructure is mostly \\
& concerned with the delivery of experience \\
& and perception (e.g. Ada Experience [18], \\
& TMN Bluestore [59]). \\
\hline Interaction & The interaction interfaces are at the periph- \\
& ery of the user's attention, resulting in \\
& interaction models that are non-invasive \\
& and non-obtrusive, thus not interrupting the \\
& user. The design of the environment is \\
& focused on enhancing the user experience \\
& (e.g. Car windshield by General Motors \\
& [23], World Cup Adidas Ball [63]). \\
\hline Environments are designed to enable an \\
understanding of current contexts. As a \\
result, systems achieve interpretation, ra- \\
ther than just descriptions (e.g. Prada Shop \\
[46], Ada Experience [18]). \\
\hline The adaptation is taken upon a proactive \\
level, based on history, user profiles and \\
predictions of user needs, requirements, \\
desires, explicit and implicit inputs and the \\
surrounding context (e.g. TMN Bluestore \\
[59], Prada Shop [46]). \\
\hline Ad this level, the attention is on the aes- \\
thetic effect of the experience: the impact \\
that the appearance and perception of a \\
designed artefact have on the user's emo- \\
tional and mental world. The technology is \\
present to enhance an existing real envi- \\
ronment, with the goal of achieving posi- \\
tive experiences, given that the function is \\
integrated in a context, instead of being \\
isolated (e.g. Songdo's Ubiquitous City \\
[45], Prada Shop [46], TMN Bluestore \\
[59]).
\end{tabular}

signing the experience and taking into consideration what and how media will induce these within the space. It is important to remember the perception of an environment as a first person experience and is strongly dependent on a variety of personal variables, such as history, personality, mood, etc. Every time, every one of us will have a different experience of the same space. We externalise and share our experiences by turning them into words and sentences. Unfortunately not all experiences are declarative and some cannot be put into words. We allow for the expression of one's experience through other means. Actions, behaviours and movements are used for expression. They become part of the user behaviour that we want to translate into a ritual within the environment.

We have analysed this new approach, and compared with the System-Centred Approach previously defined in Table 1. In Table 2 we provide clarification 
on the different features, in regards of the needs and expectations for a responsive environment system:

Table 2 shows there are now numerous projects that address several criteria simultaneously. The field of research has matured and has adopted what we call a User-Centred Approach. This approach is centred on the experience that users can obtain from different spaces, rather than simply on the display of exploration of the technology used. In this context, the enhancement of media and technology is there to assist the experience, and not as a mean to deliver an experience of media and technology per se. It is also a user-centred approach that places the initiative on the side of the user [3], meaning that decisions and behaviour of the user trigger the interaction and events that occur in the environment. This requires the involvement of different disciplines, or field of expertise, as opposed to the approaches observed in most AmI systems, that mainly involve experts from the field of engineering and computer science.

Engineering, design and social sciences are necessary to respond to both functional and conceptual requirements (will the system conceived fit to what the user will be asking of it?) in order to achieve a successful responsive environment [31]. By engineering, we mean, for example, electronics and computer science. By design, we mean, for example interaction and experience design. And finally, by social sciences, we mean social interaction and psychology, for example.

A responsive environment is also a space that invites certain emotions, actions and state of mind. Firstly, because it should somehow create an atmosphere within the environment that, on its own, contributes to the creation of a sort of user moods. Coming back to the TMN Bluestore, the interactive playground provides an entertainment experience that can change the mindset of visitor from "buying" mood to "enjoyment" mood.

Secondly, because using the environment as a platform for interaction with content, information or services allows users to interact with this information in a natural way, having the feeling that there is a mutual understanding between them and the application. The Prada Shop is an interesting example of this, as the systems integrated in the shop assist the user in the specific shopping activity.

In a way some public places in cities, such as museums, where the whole environment is designed to create a certain atmosphere around the subject of the objects being exposed, are already doing. However there is limited knowledge about what actions or emotions will be triggered in this context.

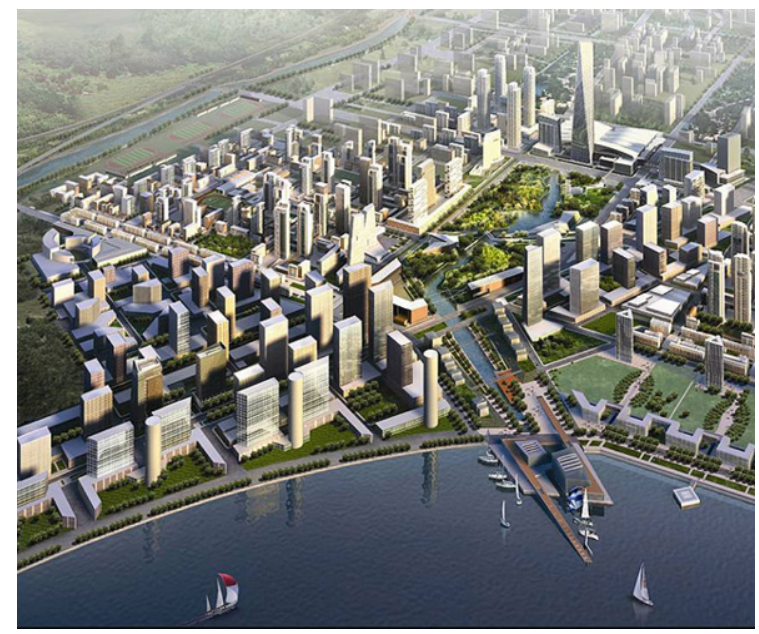

Fig. 19. Songdo's Ubiquitous City, in Incheon, South Korea, 2018 [45].

Furthermore current spaces are not often interactive or adaptive, even if the media presence is sometimes very strong. Times Square in New York can provide a very dynamic experience from the quantity of information point of view, but none of the image displays is currently interacting with any of the users in this public space.

On the other hand, very interesting challenges are being faced, with the possibility of large-scale integration of such concept, such as the Knowledge Plaza of the Osaka Station North District project [42], and, at a much larger scale, the Songdo's Ubiquitous City [45] in Incheon, South Korea. This massive responsive environment (see Fig. 19) is currently being built from scratch, where the different environments that are being developed are centred on the user needs and the way the different necessary services are there to be provided.

\section{Responsive environments at the Department of Industrial Design of the Eindhoven University of Technology}

We aim to develop a responsive environment that is receptive to its users. This is an approach where the environment adapts to the user, explicit and implicit user actions are combined with an understanding of the current context. We have defined that our context of use will be the home and the work environments, where we will be focusing on the different activities and experiences that users are subject to while in either environments. We want to develop user experi- 
ence where people feel supported and assisted by technology in their pursuit of comfort, enjoyment and positive affect.

We have set up a project about designing an adaptive office that provides its user(s) with an enhanced working experience. The enhancement is based on adaptation to the user needs and requirements, considering the specific features of the office environment (individual office, working/professional atmosphere, etc). This includes providing workers with adaptive options and possibilities that ultimately augment the level of efficiency via comfort, communication and access to services and information during the use of this space. Our first attempt at setting up an adaptive office, in the scope of responsive environments, is the installation we are currently developing in xxx. Four different components have been designed: an environment controller (called EmDis), an adaptive desk (named Equinox desk) a desk lamp (Flux), and a tea maker (Zutea).

The type of user experience we want is based on naturalness, comfort, ease of use and positive outcome, the user should experience the continuation of prevailing habits and rituals as long as they are positive. In the following sections we provide an overview of these projects. Our intention is to integrate them in a smart office for user tests and experiments.

\subsection{EmDis environment controller}

EmDis is the embodiment of the responsive environment; displaying the current status of the environment in an abstract and metaphorical way and at the same time, allowing the user to change and control the environment with simple and natural gestures.

Developed with a focus on aesthetics, shape and interaction, EmDis is a magical and beautiful gateway to and from the environment. Giving the object a magical touch will ensure that the user keeps using it with the same pleasure as derived by the first time use. EmDis is the design of an object that provides control of the environment parameters in a natural and familiar way. The first interaction is the opening and closing of the object. The design allows the user to manipulate the shape of the object. This corresponds to the openness of the environment's atmosphere. The second interaction is the heating up and cooling down of the core. This is mapped to the room temperature and to the lighting's colour temperature. The last interaction is the speed of the rotation of the core. It represents the activity level of the room and influences the background music.

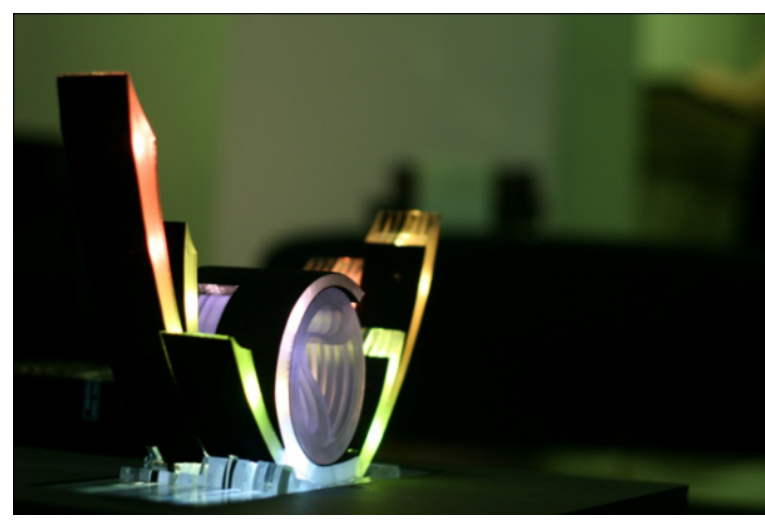

Fig. 20. EmDis Environment Controller, Netherlands, 2009.

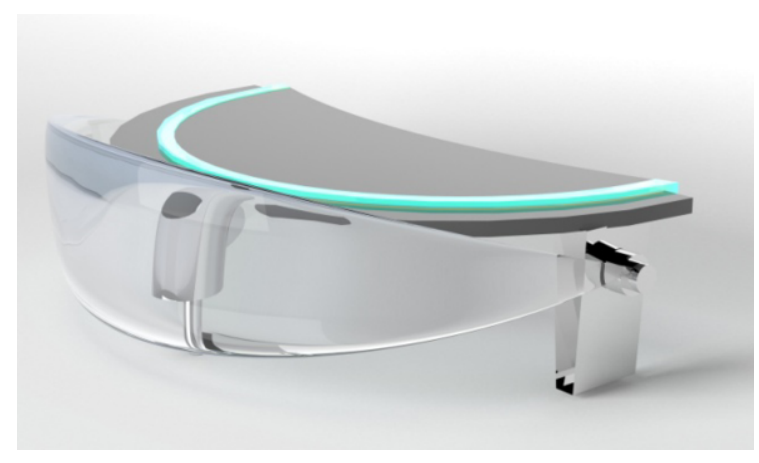

Fig. 21. Equinox Desk, Netherlands, 2009.

\subsection{Equinox desk}

Equinox is a lighting adaptive office desk and aims to address the Seasonal Affective Disorder - known also as SAD syndrome - within the context of the office environment.

Equinox is an adaptive and responsive desk that focuses on two of the main causes of SAD: low daylight intensity and cold colour temperature. Equinox relies on light therapy to prevent SAD, by compensating the cold colour of daylight in autumn and winter with a warm self-illumination. Similarly, Equinox adjusts the intensity of its self-illumination. It is designed with two lighting elements: the desktop, which provides a diffuse light, and a movable screen, that creates the illusion of a window through which the sun shines).

\subsection{Flux desk lamp}

Flux is an ambient break management system in the form of a desk lamp designed for responsive office environment. This project aims to increase the 


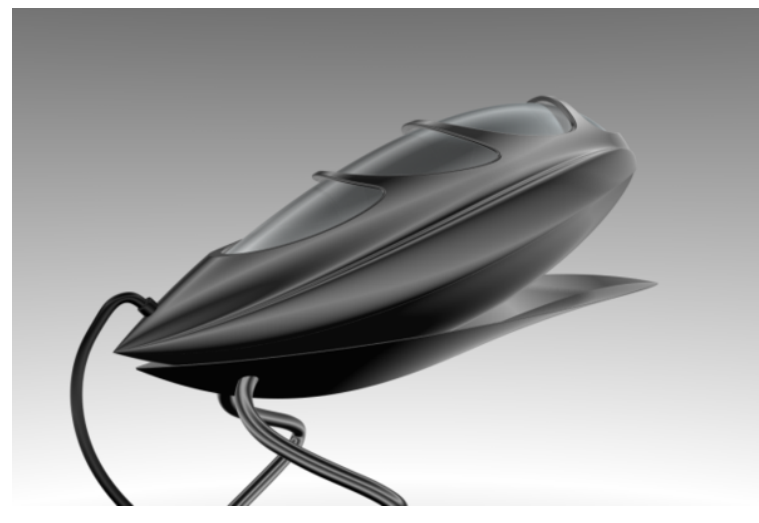

Fig. 22. Flux Desk Lamp, Netherlands, 2009.

office worker's experience by changing the way information is brought to his/her attention. Flux is designed with a focus on non-obtrusive communication and non-invasive interaction.

Positioned on the desktop, Flux invites the user to have a break when needed. Based on the principle of the Workpace software [62], now used by many information workers, Flux measures work intensity based on the number of keystrokes and mouse events within a timeframe. It compares this data to the user's stored personal break pattern and notifies the user of the necessity to have a break - generally six minutes each hour of continuous computer use. In addition, Flux tells the user whether (s)he is likely to meet a colleague during the proposed break. Flux is also promoting social connections with work colleagues. In contrast to the Workpace software, which uses disruptive pop-up windows and annoying sounds to "motivate" the user to take a break, Flux uses light and movement. In combination with the social dimension, the calm technology of Flux enhances the office worker's experience.

\subsection{Zutea tea maker}

Zutea is a ritual enhanced tea maker, and focuses on those having difficulties taking their minds of work during their work break.

The Zutea tea maker provides an intuitively made cup of tea. Tea is added manually to any flower, by pulling down the flexible stem; the user initiates the boiling process. Each stem has a length associated with a brewing time to offer the freedom to pick the desired tea strength. While the flower remains down, hot water pours in to mix with the tealeaves. The flower uprights itself, while brewing. Once the top is reached, the tea is ready. Pouring the brew in a cup

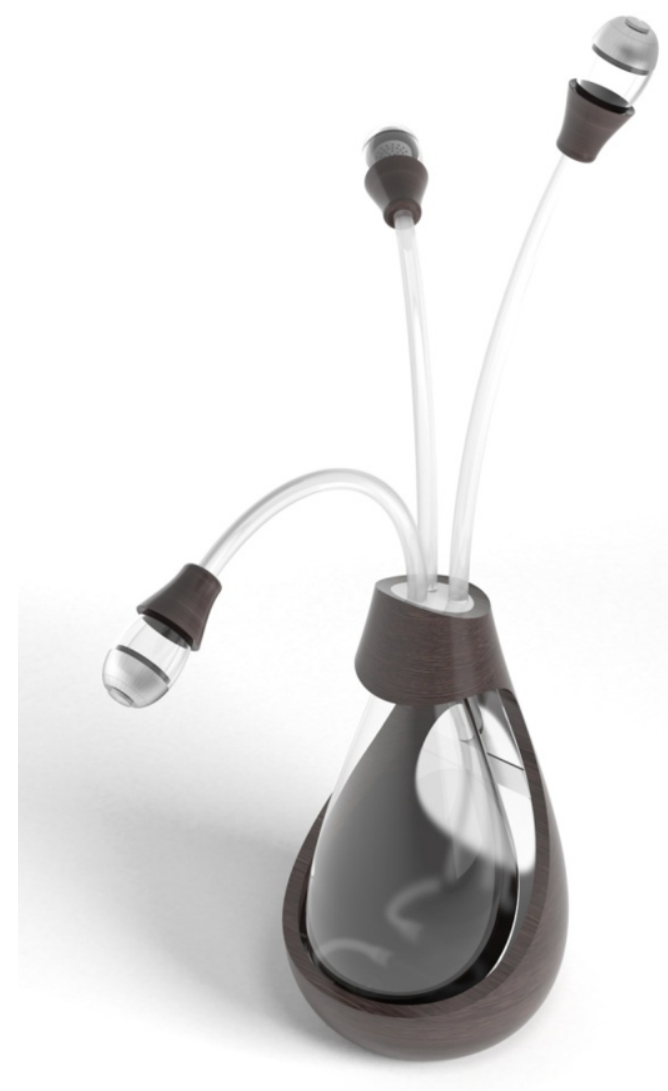

Fig.23. Zutea Tea Maker, Netherlands, 2009.

(top-lid removed) is the last action before the tea can be enjoyed. Transparent materials make the process of tea making visible and enriches the interaction with the tea maker. Many cultures embraced the healthy and relaxing beverage in which high-quality materials and attention for details in the aesthetics of products play an important role in their tea rituals. Zutea's organic shape and traditional materials, yet fully automated operation, enrich the ritual of tea making and fit neatly any modern office environment.

\section{Conclusion}

We have defined responsive environments as physical spaces that are enhanced with ambient intelligence, e.g. media and technology to provide a user experience that is interactive, rich, unique and changing. Users of the environment experience a more engaging and interesting space when compared with the original space before the enhancement. 
But why should responsive environments be a direction to follow? Using environments as platforms for new models of communication, access to information and services seems to be a step further towards a different level of engagement and improvement of the user experience. The experience would be supported by natural and intuitive interfaces that can metaphorically be connected to our notion of what is real.

This is such a new field of expertise, where different disciplines are to be combined to achieve successful results; some of the projects reviewed still don't reflect such a combination of expertise, as they were built under a system-centred approach. Many are exploring the potential of the technology, leaving user experience, needs and expectations to a second plan. The consequence is that even though environments are technically successful and functional, the experiences that they provide are not successful or enriching ones, if the effect of the novelty is put aside.

This leaves open space for opportunities for multidisciplinary teams that are user-focused to design systems that are successful both from the user and technology point of view, if criteria from both technology specifications and user requirements are taken into account. In our project for the adaptive office we have tried to set up such a multidisciplinary team, and we aim to achieve truly responsive environments.

\section{Acknowledgements}

We would like to thank Emile Aarts, from Philips Research, for his guidance during the course of this research. We would also like to thank the following students for their excellent work in producing the different components of our adaptive office: Vic van Hensberg for EmDis, Konstantinos Lioumpas for Equinox, Ard Jacobs for Flux and Ruben Meeldijk for Zutea. Finally, we would also like to thank Ad van Berlo and Corien van Berlo, from Smart Homes, for their support.

\section{References}

[1] E. Aarts (2006) Ambient Lifestyle: From Concept to Experience. Eds. E. Aarts and E. Diederiks, pp. 29-35. Amsterdam, the Netherlands: BIS Publishers.

[2] E. Aarts, B. de Ruyter (2009) New research perspectives on Ambient Intelligence. Journal of Ambient Intelligence and Smart Environments, vol. 1, pp. 5-14.

[3] E. Aarts (2009) Personal conversation with the first two authors. Held in 17 February 2008, at the Eindhoven University of Technology, Eindhoven, the Netherlands.
[4] Barclay's Interactive Walkway, Ydreams website, http:// www.ydreams.com/ydreams_2005/index.php?page $=477$.

[5] Blackbeard Connection, in nlxl website, http://nlxl.zope.nl/ 200410061097057412/200410061097057465/20041006109 7057502/200509071126075094/tContent.

[6] T. Blaine, S. Fels (2003) Contexts of Collaborative Musical Experiences. Proceedings of the 2003 Conference on New Interfaces for Musical Expression (NIME-03), pp. 129-134. Singapore.

[7] L. Bonanni (2006) Living with Hyper-reality. In Y. Cai and J. Abascal (Eds.): Ambient Intelligence in Everyday Life, LNAI 3864, pp. 130-141. Berlin: Springer.

[8] BPI Interactive Loan Store, Ydreams website, http://www. ydreams.com/ydreams 2005/index.php?page $=478$.

[9] M. Coen (1998) Design Principles for Intelligent Environments. Proceedings of the Fifteenth National Conference on Artificial Intelligence (AAAI'98), pp. 547-554. Madison, USA.

[10] Corriere della Sera: Interactive surfaces designed by iO Agency, in Corriere TV. Retrieved 15 February 2009, from http://video.corriere.it/?vxSiteId=404a0ad6-6216-4e10-abfe$\mathrm{f} 4 \mathrm{f} 6959487 \mathrm{fd} \& \mathrm{vxChannel}=$ Scienze $\&$ vxClipId $=2524$ ed624 b3c-b0d4-11dd-939a-00144f02aabc\&vxBitrate $=300$.

[11] B. Costello, L. Muller, S. Amitani, E. Edmonds (2005) Understanding the experience of interactive art: Iamascope in Beta_space. Proceedings of the second Australasian conference on Interactive entertainment, pp. 49-56. Sydney, Australia.

[12] G. Davenport, S. Agamanolis, B. Barry, B. Bradley, K. Brooks (2000) Synergistic Storyscapes and Constructionist Cinematic Sharing. IBM Systems Journal, Vol. 39, Issue 3-4, pp. 456-469. Riverton, NJ, USA.

[13] M. Davis (2003) Theoretical Foundations for Experiential System Design. Proceedings of the ETP'03, pp. 45-52. Berkeley, CA, USA.

[14] Design for future windshield, in wired magazine, "found" website section. Retrieved 16 December 2008, from http://www.wired.com/imageviewer/?imagePath=/images/ar ticle/magazine/1601/found.jpg.

[15] A.K. Dey, G.D. Abowd, D. Salber (2001) A conceptual framework and a toolkit for supporting the rapid prototyping of context-aware applications. Journal of Human-Computer Interaction, vol. 16, pp. 97-166. London, UK.

[16] P. Dourish (2001) Seeking a Foundation for Context-Aware Computing. Journal of Human-Computer Interaction, Vol. 16, pp. 229-241. London, UK.

[17] P.L. Emiliani, C. Stephanidis (2005) Universal access to ambient intelligence environments: opportunities and challenges for people with disabilities. IBM Systems Journal, Vol. 44, No. 3, pp. 605-619.

[18] K. Eng, A. Baebler, U. Bernardet, M. Blanchard, M. Costa, T. Delbruck, R. J. Douglas, K. Hepp, D. Klein, J. Manzolli, M. Mintz, F. Roth, U. Rutishauser, K. Wassermann, A.M. Whatley, A. Wittmann, R. Wyss, P.F.M.J. Verschure (2003) Ada - Intelligent Space: An artificial creature for the Swiss Expo.02. Proceedings of the 2003 IEEE International Conference on Robotics and Automation (ICRA 2003), Vol. 3, pp. 4154-4159.

[19] Experience Lab, Philips Research Website, http://www. research.philips.com/focused/experiencelab.html.

[20] S. Fels, S.J. Simoff (1999) Quantifying Beauty: An Information System for Evaluating Universal Aesthetics. Proceedings of the Western Australian Workshop on Information Systems Research (WAWISR), pp. 262-267. Perth, Australia. 
[21] S. Fels (2000) Intimacy and Embodiment: Implications for Art and Technology. Proceedings of the 2000 ACM workshops on Multimedia, pp. 13-16. Los Angeles, CA, USA.

[22] J. Forlizzi, K. Battarbee (2004) Understanding Experience in Interactive Systems. Proceedings of the 5th conference on Designing interactive systems: processes, practices, methods and techniques, pp. 261-268. Cambridge, USA.

[23] General Motors designs windshield that enhances objects to help seniors, in New York Daily News. Retrieved 14 December 2008, from http://www.nydailynews.com/autos/ 2008/08/04/2008-08-04_general_motors_designs windshield that e.html.

[24] Glowing Places, Philips website, http://www.philips.ca/mt theme_005_32 glowing places large.page.

[25] N. Graham, L. Watts, G. Calvary, J. Coutaz, E. Dubois, L. Nigay (2000) A Dimension Space of Interactive Systems within their Physical Environments. Proceedings of DIS'00, pp. 406-416. Brooklyn, New York, USA.

[26] M. Hassenzahl, N. Tractinsky (2006) User experience - a research agenda. Journal of Behaviour \& Technology Information, Vol. 25, No. 2, pp. 91-97.

[27] Interactive Ads for Shanghai Stadium Subway Station, Ydreams website, http://www.ydreams.com/ydreams_2005/ index.php?page $=470$.

[28] S. Intille (2002) Designing a Home of the Future. IEEE Pervasive Computing, vol. 1 , no. 2 , pp. 76-82.

[29] Isola dei Famosi, in Natural Interaction. Retrieved 16 January 2009, from http://www.naturalinteraction.org/index. php?entry=entry070919-123057.

[30] J. Johnson, T. L. Roberts, W. Verplank, D.C. Smith, C.H. Irby, M. Beard, K. Mackey (1989) The Xerox Star: A Retrospective. Computer, vol. 22, no. 9, pp. 11-29.

[31] S. Jones (2005) A Cultural Systems Approach to Collaboration in Art \& Technology. Proceedings of the 5th conference on Creativity \& Cognition, pp. 76-85, London, UK.

[32] M. Krueger (1977) Responsive Environments. Proceedings of the 1977 National Computer Conference, pp. 423-433. New York, USA.

[33] M. Kuzmanovic, N. Gaffney (2005) Human-Scale Systems in Responsive Environments. IEEE Multimedia, vol. 12, no. 1, pp. 8-13.

[34] E. Law, V. Roto, A. Vermeeren, J. Kort, M. Hassenzahl (2008) Towards a Shared Definition of User Experience. CHI 2008 Proceedings - Special Interest Groups, pp. 23952398. New York, USA.

[35] Living memory project website. Retrieved 15 January 2009, from http://www.idemployee.id.tue.nl/g.w.m.rauterberg/ Movies/Living\%20Memory/Living\%20Memory.htm.

[36] A. Marx (1994) Using Metaphor Effectively in User Interface Design. Proceedings of Conference on Human Factors in Computing Systems, pp. 379-380. Boston, Massachusetts, USA.

[37] M. McLuhan (1964) Understanding Media: the Extension of Man. Routledge \& Kegan Paul, London, UK.

[38] S. Meyer, A. Rakotonirainy (2003) A Survey of Research on Context-Aware Homes. Proceedings of the Australasian information security workshop conference on ACSW frontiers 2003, Vol. 21, pp. 159-169. Adelaide, Australia.

[39] MIT Responsive Environments Group projects' website. Retrieved 28 October 2008, from http://www.media.mit.edu/ resenv/projects.html.

[40] A. Monk, M. Hassenzahl, M. Blythe, D. Reed (2002) Funology: Designing Enjoyment. Proceedings of the CHI 2002, pp. 924-925. Minneapolis, MN, USA.

[41] I. Nielsen, G. Pullin (2005) A Simple Secret for Design. ACM Interactions, vol. 12 (issue 4), pp. 48-50.
[42] Osaka North Station District Scheme, http://www.kitayard.com/en/index.html.

[43] M. Pantic (2006) Face for Ambient Interface. In Y. Cai and J. Abascal (Eds.): Ambient Intelligence in Everyday Life, LNAI 3864, pp. 32-66. Berlin: Springer.

[44] J. Paradiso (2005) New Sensor Architectures for Responsive Environments. IEE Digest, Vol. 2005, Issue 11059, Vol. 1, pp. 15-24.

[45] M.G. Petersen, O.S. Iversen, P.G. Krogh, M. Ludvigsen (2004) Aesthetic interaction: a pragmatist's aesthetics of interactive systems. Proceedings of the 5 th conference on Designing interactive systems: processes, practices, methods, and techniques, pp. 269-276. New York, NY, USA.

[46] Philips Research Lab: Shop Lab, in Philips Research Centre Online. Retrieved 26 September 2008, from http://stream. hightechcampus.nl/shoplab/200711-shoplab.wmv.

[47] T. Rodden, S. Benford (2003) The Evolution of Buildings and Implications for the Design of Ubiquitous Domestic Environments. Proceedings of CHI 2003, Vol. 5, Issue 1, pp. $9-16$.

[48] V. Roto, H. Rantavuo, K. Väänänen-Vainio-Mattila (2009) Evaluating User Experience of Early Product Concepts. Proceeding of the International Conference on Designing Pleasurable Products and Interfaces DPPI09, pp. 1-10. Compiegne, France.

[49] B. Salem, J. Alves Lino, M. Rauterberg (2010) SmartEx: A Case Study on User Profiling and Adaptation in Exhibition Booths. Journal of Ambient Intelligence and Humanized Computing. New York: Springer, In Press.

[50] B. Salem, M. Rauterberg (2004) Multiple user profile merging: Key Challenges for Aware Environments. In P. Markopoulos, B. Eggen, E. Aarts, J. Crowley (Eds.), Ambient Intelligence: second European Symposium, EUSAI 2004 (Lecture Notes in Computer Science, pp. 196-206). Berlin: Springer.

[51] S. Shafer, B. Brumitt, J. Cadiz (2001) Interaction issues in Context-Aware Intelligent Environments. Journal of Human-Computer Interaction, vol. 16, pp. 363-378. London, UK.

[52] T.B. Sheridan (1999) Descartes, Heidegger, Gibson, and God: Towards an Ecletic Ontology of Presence. Presence, Vol. 8, pp. 551-559. Cambridge, Massachusetts, USA.

[53] Smart Home, Smart Homes Foundation website, http://www. smart-homes.nl/engels-homepage/engels-inleiding/.

[54] Songdo's Ubiquitous City, in Songdo uLife. Retrieved 7 January 2009, from http://www.songdo.com/page1992.aspx.

[55] F. Sparacino (2002) Narrative Spaces: Bridging Architecture and Entertainment Via Interactive Technology. Proceedings of the 6th International Conference on Generative Art, pp. 1-15. Milan, Italy.

[56] K. Stathis, O. de Bruijn, S. Macedo, (2002) Living memory: agent-based information management for connected local communities. Interacting with Computers, vol. 14(6), pp. 663-688.

[57] C. Stephanidis (2001) User interfaces for all: new perspectives into HCI. In User Interfaces for All - Concepts, Methods and Tools. Ed. C. Stephanidis, Lawrence Erlbaum Associates, Mahwah, New Jersey, USA.

[58] M. Strohbach, H. Gellersen, G. Kortuem, C. Kray (2004) Cooperative Artifacts: Assessing Real World Situations with Embedded Technology. Proceedings of UbiComp 2004, pp. 250-267. Berlin, Germany.

[59] TMN Bluestore, Ydreams website, http://www.ydreams. com/ydreams_2005/index.php?page $=472$. 
[60] A. Valli (2007) Natural Interaction White Paper. Retrieved in 15 March 2008, from http://www.naturalinteraction.org/ images/whitepaper.pdf.

[61] M. Weiser (1993) Some Computer Issues in Ubiquitous Computing. Communications of the ACM, Vol. 36, N. 7 , pp. 75-84.
[62] Workpace Website, http://www.workpace.com/.

[63] World Cup Adidas Eye Ball, Ydreams website, http://www. ydreams.com/ydreams_2005/index.php?page $=461$. 